\title{
Ubiquitous presence of gluconeogenic regulatory enzyme, fructose-1,6-bisphosphatase, within layers of rat retina
}

\author{
Piotr Mamczur • Jakub Mazurek • Darek Rakus
}

Received: 13 April 2010 /Accepted: 14 June 2010 /Published online: 8 July 2010

(C) The Author(s) 2010. This article is published with open access at Springerlink.com

\begin{abstract}
To shed some light on gluconeogenesis in mammalian retina, we have focused on fructose-1,6bisphosphatase (FBPase), a regulatory enzyme of the process. The abundance of the enzyme within the layers of the rat retina suggests that, in mammals in contrast to amphibia, gluconeogenesis is not restricted to one specific cell of the retina. We propose that FBPase, in addition to its gluconeogenic role, participates in the protection of the retina against reactive oxygen species. Additionally, the nuclear localization of FBPase and of its binding partner, aldolase, in the retinal cells expressing the proliferation marker Ki-67 indicates that these two gluconeogenic enzymes are involved in non-enzymatic nuclear processes.
\end{abstract}

Keywords Fructose-1,6-bisphosphatase - Aldolase ·

Astrocytes · Isozymes · Development · Proliferation ·

Retina $\cdot$ Rat

\section{Introduction}

Glycogen, the major energy reserve in the retina, is stored predominantly in Müller cells (Poitry-Yamate and Tsacopoulos

This work was supported by a Zoological Institute of Wroclaw University research grant.

Electronic supplementary material The online version of this article (doi:10.1007/s00441-010-1008-2) contains supplementary material, which is available to authorized users.

P. Mamczur · J. Mazurek · D. Rakus $(\bowtie)$

Department of Animal Molecular Physiology,

Institute of Zoology, Wroclaw University,

Cybulskiego 30,

50-205 Wroclaw, Poland

e-mail: drakus@biol.uni.wroc.pl
1991), the prevalent glial element of vertebrate retina. Retinal glycogen is presumed to provide carbohydrate support to retinal neurons when the glucose supply of the tissue falls below its needs (Poitry-Yamate and Tsacopoulos 1992; PoitryYamate et al. 1992).

In the retina, glycogen synthesis from carbohydrates precursors, viz., glyconeogenesis, might be a mechanism of metabolite and neurotransmitter (e.g., lactate and glutamate) removal during periods of high metabolic activity of retinal neurons and photoreceptors (Goldman and Witkovsky 1987; Coffe et al. 2004). Evidence for the occurrence of glyco- and/or gluconeogenesis (synthesis of glucose from non-carbohydrates) within the vertebrate retina has been demonstrated by Goldman (1988), who has found that amphibian retina contains a full complement of gluconeogenic enzymes, and that $11 \%-15 \%$ of the glucosyl units in retinal glycogen are derived from $\mathrm{C} 3$ metabolites of the glycolytic pathway, presumably from lactate. Retinal gluconeogenesis is thought to be restricted to the Müller cell fraction in Amphibia (Goldman 1990). However, until now, no definitive evidence for the presence of gluconeogenic enzymes in the retina of other vertebrate groups has been presented.

To gain insight into the presence and localization of gluconeogenesis in the mammalian retina, we have studied the retinal distribution, subcellular localization, enzymatic activity, and isozyme pattern of fructose-1,6-bisphosphatase (FBPase), a regulatory enzyme of glucose and glycogen synthesis from non-carbohydrates, in structures of the rat retina. On the basis of co-localization studies of FBPase with its binding partner, viz., aldolase (EC 4.1.2.13; Rakus and Dzugaj 2000), and with structural proteins, e.g., vimentin, glial fibrillary acidic protein (GFAP), and $\alpha$ tubulin, we hypothesize that Müller cells are not the only retinal cells in which the conversion of non-carbohydrates 
into glycogen (or at least into glucose-6-phosphate) occurs. We also propose that, in addition to its expected role in retinal glyconeogenesis, FBPase might be involved in the protection of the retina against the toxic effects of oxygen.

Additionally, the nuclear presence of the enzyme and of aldolase in cells of the developing, but not adult, retina indicates that both the enzymes are also engaged in some non-enzymatic nuclear functions. The physiological meaning of these findings is discussed.

\section{Materials and methods}

Adult and newborn (4-day-old) rats (Rattus norvegicus) were obtained from the Medical Academy's Animal Quarters (Wroclaw, Poland). The animals were decapitated according to the procedure approved by a Local Ethics Committee in Wroclaw (permission no. 87/2006). Polyester wax was obtained from Science Services (Munich, Germany). Ki-67 (NCL-Ki-67p) was purchased from Biokom (Janki, Poland). Other reagents were from Sigma-Aldrich (Poznan, Poland).

Isolation of RNA and reverse transcription with polymerase chain reaction

Total RNA was isolated from $50 \mathrm{mg}$ frozen $\left(-70^{\circ} \mathrm{C}\right)$ rat retina by using the GenElute Mammalian Total RNA Miniprep Kit according to the manufacturer's instructions. For reverse transcription with the polymerase chain reaction (RT-PCR), mRNA was transcribed into cDNA with the Enhanced Avian HS RT-PCR Kit. The cDNA was a PCR template in a reaction mixture containing $2.5 \mathrm{U}$ JumpStart Accu Taq LA DNA polymerase, 5 mM TRIS-HCl (pH 9.3), $2.5 \mathrm{mM} \mathrm{MgCl} 2,15 \mathrm{mM}$ ammonium sulfate, $0.1 \%$ Tween 20, $2 \%$ dimethylsulfoxide, dNTPs $(0.4 \mathrm{mM}$ each), and appropriate rat FBPase-specific primers $(0.5 \mu \mathrm{M}$ each). To screen the expression of FBPase isozymes in retinal cells, rat liver-FBPase-specific primers (5'-CGTCAACTGCTT CATGCTGG; 5'-GTGACTCTCGAGCTCTGCTC) and rat muscle-FBPase-specific primers (5'-GAGTGGATCTCTT CATGCTG; 5'-GTGAATGCTCTCAGGCTTTAC) were used. The primers were designed to amplify the fragments of mRNA ( 395 bases for the muscle isozyme and 518 bases for the liver) coded by more than one exon in the genomic DNA (the length of amplified genomic DNA fragments by using rat muscle-FBPase-specific primers and rat liverFBPase-specific primers should be equivalent to $9154 \mathrm{bp}$ and to $6405 \mathrm{bp}$, respectively). Thirty-five PCR cycles were performed, each consisting of denaturation at $94^{\circ} \mathrm{C}$ for $1 \mathrm{~min}$, annealing at $53^{\circ} \mathrm{C}$ for $1 \mathrm{~min}$, and extension at $72^{\circ} \mathrm{C}$ for $1 \mathrm{~min}$. PCR-derived DNA fragments were electrophoresed on $2 \%$ agarose gel supplemented with $0.01 \%$ ethidium bromide and examined under UV light (Vilber Lourmat, Eberhardzell, Germany).

Determination of enzymatic activity

FBPase activity was determined as previously described (Rakus and Dzugaj 2000). Phosphofructokinase-1 (PFK) activity measurement was carried out according to Ling et al. (1965) with modifications: $1 \mathrm{ml}$ PFK assay mixture contained $1 \mathrm{mM}$ fructose-6-phosphate, $0.02 \mathrm{mM}$ fructose2,6-bisphosphate, $0.2 \mathrm{mM} \mathrm{NADH}, 1 \mathrm{U}$ aldolase, $5 \mathrm{U}$ triose-3-phosphate isomerase, $5 \mathrm{U}$ glycerol-3-phosphate dehydrogenase, $0.02 \mathrm{mM}$ AMP, $1 \mathrm{mM}$ ATP in the relevant buffer $(50 \mathrm{mM}$ bis-TRIS propane, $0.25 \mathrm{mM}$ EDTA, $1.25 \mathrm{mM} \mathrm{MgCl}, 150 \mathrm{mM} \mathrm{KCl} ; \mathrm{pH} 7.4,37^{\circ} \mathrm{C}$ ). All spectrophotometric measurements were performed with an Agilent 8453 diode array spectrophotometer.

In order to determine FBPase and PFK activities in the retina, dissected rat eyes were placed into Hanks' balanced salt solution $\left(4^{\circ} \mathrm{C}\right)$, and the retinas were immediately gently peeled away. Then $30 \mathrm{mg}$ either adult or newborn rat retinas were homogenized in $0.3 \mathrm{ml}$ homogenization buffer (100 mM KCl, $1 \mathrm{mM}$ dithiothreitol, $5 \mathrm{mM}$ EDTA, $5 \mathrm{mM}$ ethylene-bis[oxyethylenenitrilo]tetraacetic acid, $1 \mathrm{mM}$ phenylmethylsulfonyl fluoride, $0.014 \mathrm{mg} / \mathrm{ml}$ leupeptin, $1 \%$ Triton X-100, $20 \mathrm{mM}$ HEPES; $\left.\mathrm{pH} 7.4,4^{\circ} \mathrm{C}\right)$. The homogenates were subsequently centrifuged $(20 \mathrm{~min}$, $20,000 \mathrm{~g}, 4^{\circ} \mathrm{C}$ ), and the supernatant fraction was assayed for enzymes activities.

For all the measured enzymes, one unit of enzyme activity is defined as the amount of the enzyme that catalyzes the transformation of $1 \mu \mathrm{mol}$ substrate per minute.

Isolation and primary cell culture of Müller cells

Müller cells were separated from rat retina according to Gerhardinger et al. (2005), and their primary culture was established as described previously (Guidry 1996).

Immunocytochemistry

Rabbit polyclonal antisera against muscle aldolase or muscle FBPase were produced and purified as described previously by Mamczur and Dzugaj (2004) and Gizak and Dzugaj (2003), respectively. The antisera were partially purified by using A-protein-agarose gel chromatography according to manufacturer's procedure (HiTrap Protein A HP, GE Healthcare). To check the specificity of the antisera, preabsorption experiments and immunoblotting were performed as described by Towbin et al. (1979) with extracts from rat retina and purified muscle FBPase and muscle aldolase as a control (see Electronic supplementary material). 
Adult and newborn rat retinas were fixed in Carnoy's fluid and embedded in polyester wax. Dewaxed tissue sections were used to study the distributions of the proteins of interest. For co-localization experiments, sections of the adult rat retina were incubated overnight at $4^{\circ} \mathrm{C}$ with rabbit anti-FBPase antiserum (protein concentration: $100 \mu \mathrm{g} / \mathrm{ml}$ ) together with mouse antiserum against aldolase A $(100 \mu \mathrm{g} / \mathrm{ml})$ or with mouse immunoglobulins against GFAP $(1 \mu \mathrm{g} / \mathrm{ml})$ and $\alpha$-tubulin $(15 \mu \mathrm{g} / \mathrm{ml})$. To test the co-localization of the proteins in the neonatal retina, rabbit anti-Ki-67 $\operatorname{IgG}$ (dilution: 1:1000) was incubated overnight at $4{ }^{\circ} \mathrm{C}$ separately or together with either mouse anti-aldolase A $(100 \mu \mathrm{g} / \mathrm{ml})$ or mouse anti-FBPase $(100 \mu \mathrm{g} / \mathrm{ml})$ antisera with rat neonatal ratinal sections. The sections were subsequently incubated for $30 \mathrm{~min}$ at room temperature with the appropriate pairs of secondary fluorophore-labeled antibodies (dilution: 1:1000): goat anti-rabbit-tetramethylrhodamine isothiocyanate (TRITC), goat anti-rabbit-fluorescein isothiocyanate (FITC), goat anti-mouse-TRITC, and goat anti-mouse-FITC.

Freshly isolated Müller cells were fixed in 4\% paraformaldehyde (PFA) in PBS (phosphate-buffered saline: $137 \mathrm{mM} \mathrm{NaCl}, 2.7 \mathrm{mM} \mathrm{KCl}, 8 \mathrm{mM} \mathrm{Na} 2 \mathrm{HPO}_{4}, 1.5 \mathrm{mM}$ $\mathrm{KH}_{2} \mathrm{PO}_{4} ; \mathrm{pH} 7.5$, room temperature) for $10 \mathrm{~min}$, then centrifuged $(300 \mathrm{~g}, 10 \mathrm{~min}$, room temperature), washed twice in PBS, and centrifuged as above. Finally, a drop of the cells suspended in PBS was placed on a microscopic slide and air-dried for $15 \mathrm{~min}$ at $37^{\circ} \mathrm{C}$. The primary cell cultures were fixed for $15 \mathrm{~min}$ at room temperature in $4 \%$ PFA, washed with PBS $(2 \times 10 \mathrm{~min})$, and used for immunofluorescent studies.

Before the immunostaining procedure, the membranes of freshly isolated Müller cells and primary cell cultures were permeabilized in $0.3 \%$ Triton X-100 in PBS (15 min, room temperature). Subsequently, overnight incubation with the primary antibodies was performed at $4^{\circ} \mathrm{C}$. For co-localization experiments, rabbit anti-FBPase serum $(100 \mu \mathrm{g} / \mathrm{ml})$ was used jointly with either mouse anti-vimentin $(1: 100)$ or mouse FITC-labeled anti- $\alpha$-tubulin antibodies $(15 \mu \mathrm{g} / \mathrm{ml})$, followed by incubation (30 $\mathrm{min}$, room temperature) with the relevant antibodies labeled with fluorophores (dilution: 1:1000): goat anti-mouse-TRITC, goat anti-rabbit-FITC, and goat antirabbit-TRITC.

To test the co-localization of aldolase isoforms, the tissue sections and cultured Müller cells were incubated with both mouse anti-aldolase A serum $(100 \mu \mathrm{g} / \mathrm{ml})$ and rabbit antialdolase $\mathrm{C}$ immunoglobulins $(0.8 \mu \mathrm{g} / \mathrm{ml})$, followed by the incubation (30 $\mathrm{min}$, room temperature) with goat antimouse TRITC-conjugated and goat anti-rabbit FITCconjugated antibodies.

Tissue sections, isolated cells, and cell cultures were counterstained with 4,6-diamidino-2-phenylindole (DAPI; $0.5 \mu \mathrm{g} / \mathrm{ml}, 5 \mathrm{~min}$, room temperature) or propidium iodide $\left(2 \mu \mathrm{g} / \mathrm{ml}, 30 \mathrm{~min}, 37^{\circ} \mathrm{C}\right)$ in order to visualize cell nuclei. To avoid the unspecific binding of immunoglobulins, the tissue sections and the cells were incubated with $5 \%$ bovine serum albumin (BSA) in PBS for $1 \mathrm{~h}$ at room temperature before the application of the primary antibodies. Excess primary and secondary antibodies were removed by intensive washes in $0.1 \%$ Triton X-100/PBS. All secondary antibodies were diluted in PBS containing $0.5 \%$ BSA. Primary antibodies were omitted in control reactions.

Images of adult rat retina were obtained by using an Olympus IX71 inverted microscope. An Olympus FV1000 confocal microscope was employed to study the subcellular localization of proteins in the isolated Müller cells, in their primary cultures, and in sections of newborn rat retina. The degree of co-localization, expressed as the Pearson's correlation coefficient (the proportion of all red intensities that have green components among all red intensities), was assessed by the co-localization analysis function of the Olympus Fluoroview software (version 1.7c).

\section{Results}

As no literature on FBPase in mammalian retina exists, we first aimed to determine the activity, isozyme-type distri-

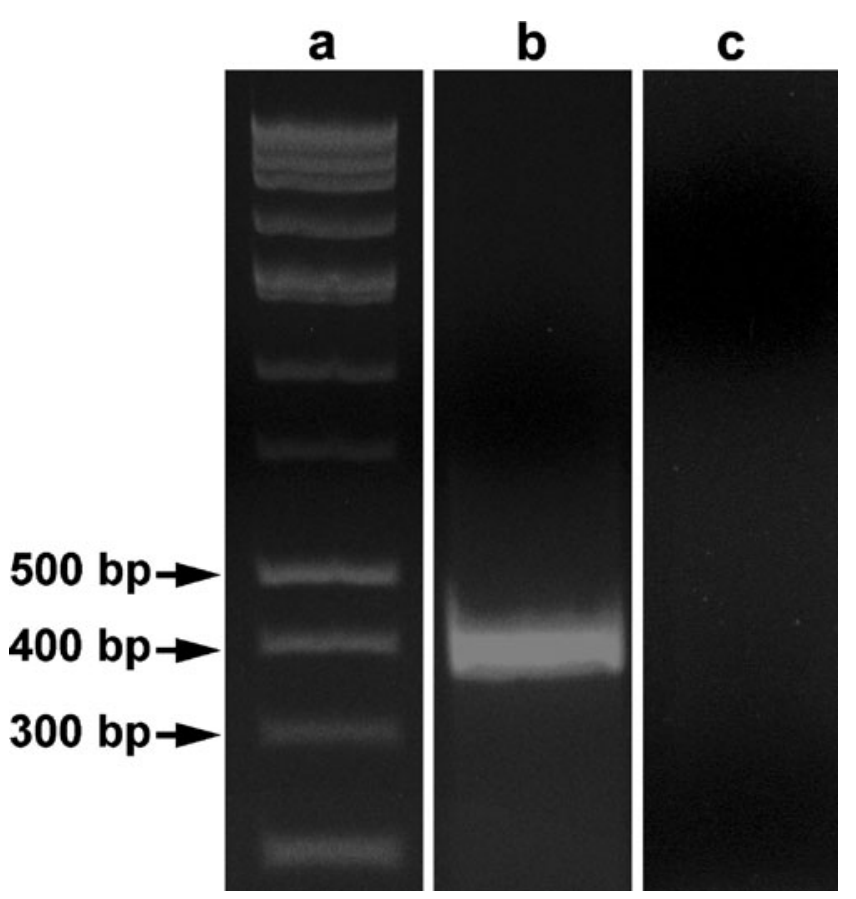

Fig. 1 Only the muscle FBPase isozyme is expressed in adult rat retina. Results of electrophoresis of samples after polymerase chain reaction. Detection of FBPase isoforms was performed with cDNA synthesized from total RNA isolated from rat retina. Lane a DNA length standard (DirectLoad Wide Range DNA Marker, Sigma), lane $b$ specific primers for rat muscle FBPase, lane $c$ specific primers for rat liver FBPase 
bution between the layers, and subcellular localization of the enzyme in rat retina cells. The measured activity of FBPase was $0.59 \pm 0.04 \mathrm{mU} / \mathrm{mg}(n=5)$ of retinal proteins in adult rats and $0.44 \pm 0.15 \mathrm{mU} / \mathrm{mg}(n=5)$ in newborns. These values were similar to that previously reported for the amphibian retina (0.83 mU/mg; Goldman 1988).

Nevertheless, the measured activities were low. Therefore, we postulated that FBPase might be involved in the regulation of the rate of glycolytic flux (forming, together with PFK, the so-called "substrate cycle") rather than in gluconeogenesis. To validate our hypothesis, we tested the retina for the PFK activity. The tissue homogenate exhibited a high PFK activity level $(228 \pm 77 \mathrm{mU} / \mathrm{mg}$ protein; $n=4)$, comparable with that measured in other tissues (Oskam et al. 1985), and about 400-500 times higher than the activity of FBPase, making the involvement of the substrate cycle unlikely.

To determine which isozyme of FBPase was expressed in the rat retina, PCR was performed with cDNA synthesized from total RNA isolated from the whole adult retina and by using primer pairs specific for the muscle and liver FBPases. The specificity of the primers was checked by PCR with cDNA synthesized from total RNA isolated from rat liver and muscle (see Electronic supplementary material). An electrophoretic analysis of PCR products showed a specific band of the expected length of $383 \mathrm{bp}$ only when the muscle-specific primers were used (Fig. 1). This suggests that the muscle isozyme is exclusively expressed in rat retinal cells.

To identify which cell populations within the rat retina expressed FBPase, we used immunofluorescence techniques and confocal microscopy. In radial sections of the rat retina, the use of antiserum against muscle FBPase revealed immunoreactivity within several layers: within the inner plexiform layer (IPL), outer plexiform layer (OPL), and outer limiting membrane and within the inner segments of photoreceptors (Fig. 2). Double-labeling with antibodies against $\alpha$-tubulin (Fig. 2a-d), aldolase A (Fig. 2e-h), or GFAP (Fig. 2i-1) in combination with antibodies directed against FBPase demonstrated at least partial co-localization of FBPase with these proteins. The FBPase fluorescence was particularly visible in the radially aligned elements of the retina suggesting that the enzyme was localized mainly in the Müller cells. Indeed, freshly isolated rat Müller cells

Fig. 2 Immunofluorescent double-labeling of radial sections of rat retina. a-d Double-labeling with antibodies against $\alpha$-tubulin (a) and FBPase (b) and merged image of a-c (d). e-h Double-labeling with antibodies against muscle aldolase (e) and FBPase (f) and merged image of $\mathbf{e}-\mathbf{g}(\mathbf{h})$. iI Double-labeling with antibodies against glial fibrillary acidic protein (GFAP; i) and FBPase (j) and merged image of i-k (l). c, g, k DAPI (4,6-diamidino-2phenylindole)-counterstained nuclei ( $G C L$ ganglion cell layer, $I P L$ inner plexiform layer, $I N L$ inner nuclear layer, $O P L$ outer plexiform layer, $O N L$ outer nuclear layer, ISPR inner segments of photoreceptors, $O S P R$ outer segments of photoreceptors, arrows outer limiting membrane). Bars $40 \mu \mathrm{m}$
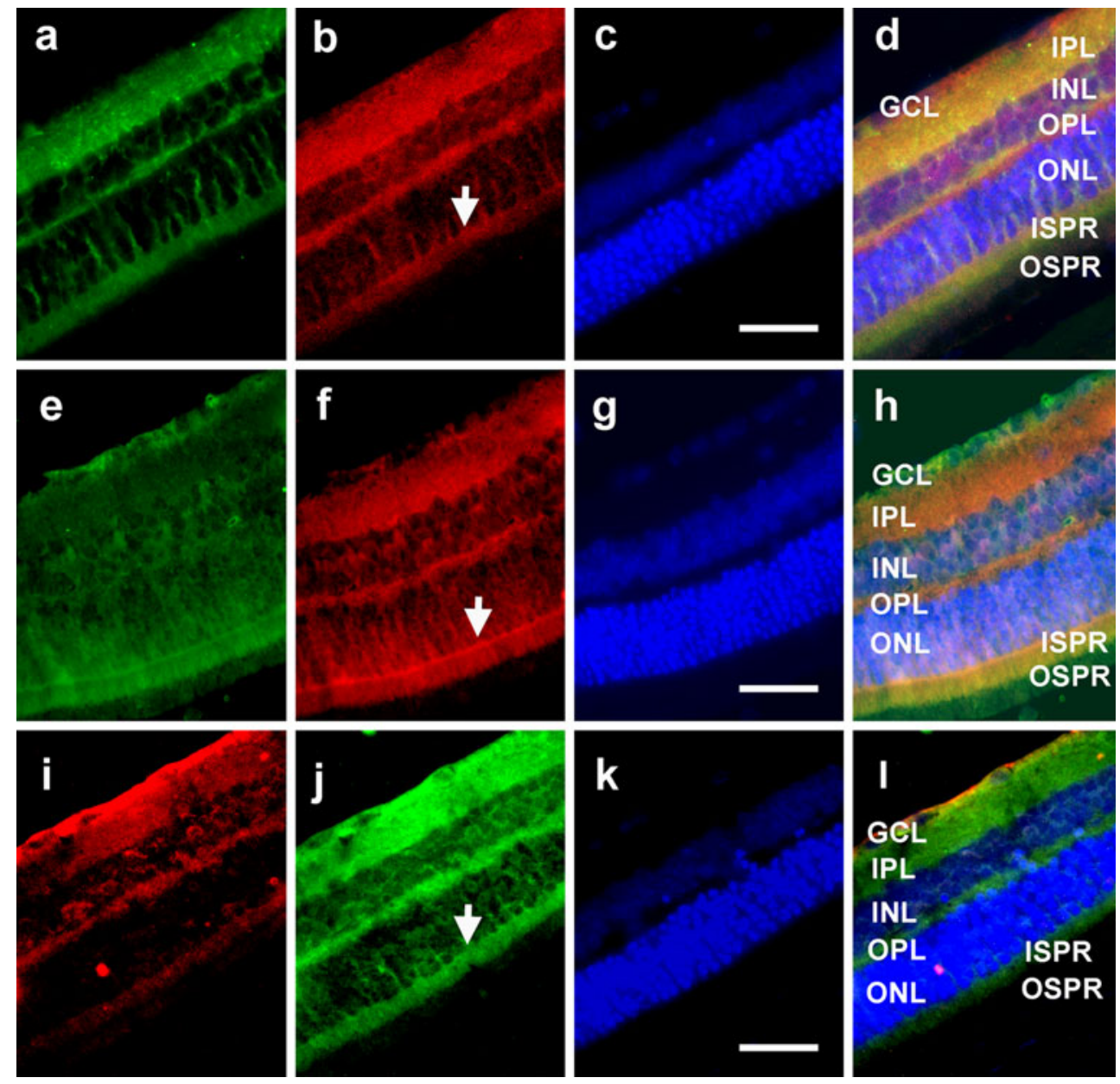
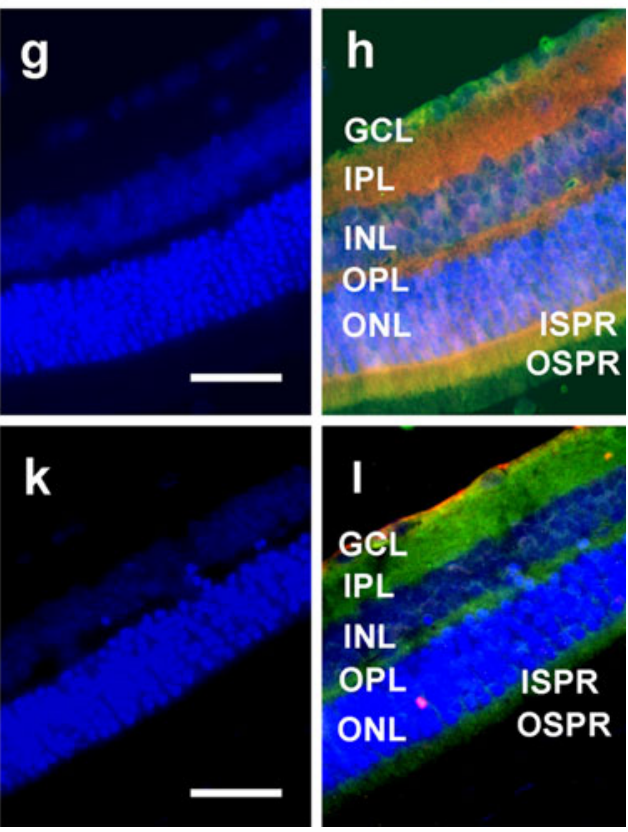
treated with antibodies against vimentin, a specific marker of these cells (Guidry 1996; Ishii et al. 1997), showed relatively strong immunofluorescent signals for FBPase (Fig. 3). However, other than the Müller cells, strong FBPase-related immunoreactivity was also found in retinal astrocytes in which FBPase appeared to be co-localized with $\alpha$-tubulin (Fig. 4).

Similarly, in the cultured Müller cells, FBPase was localized in the cytoplasm where it partially co-localized with the marker for these cells, viz., vimentin (Fig. 5a-d) and with $\alpha$-tubulin (Fig. 5e-h). The Pearson's coefficient for the overlap of FBPase and $\alpha$-tubulin was approximately 0.8 , both for the cultured Müller cells (Fig. 5h) and for the retinal astrocytes (Fig. 4d).

Unexpectedly, FBPase and the muscle, but not brain, isozyme of aldolase was localized in the nuclei of some neonatal retina cells (Fig. 6). Staining with antiserum against proliferation marker $\mathrm{Ki}-67$ revealed the co-localization of aldolase A and FBPase with this marker suggesting that both the enzymes accumulated
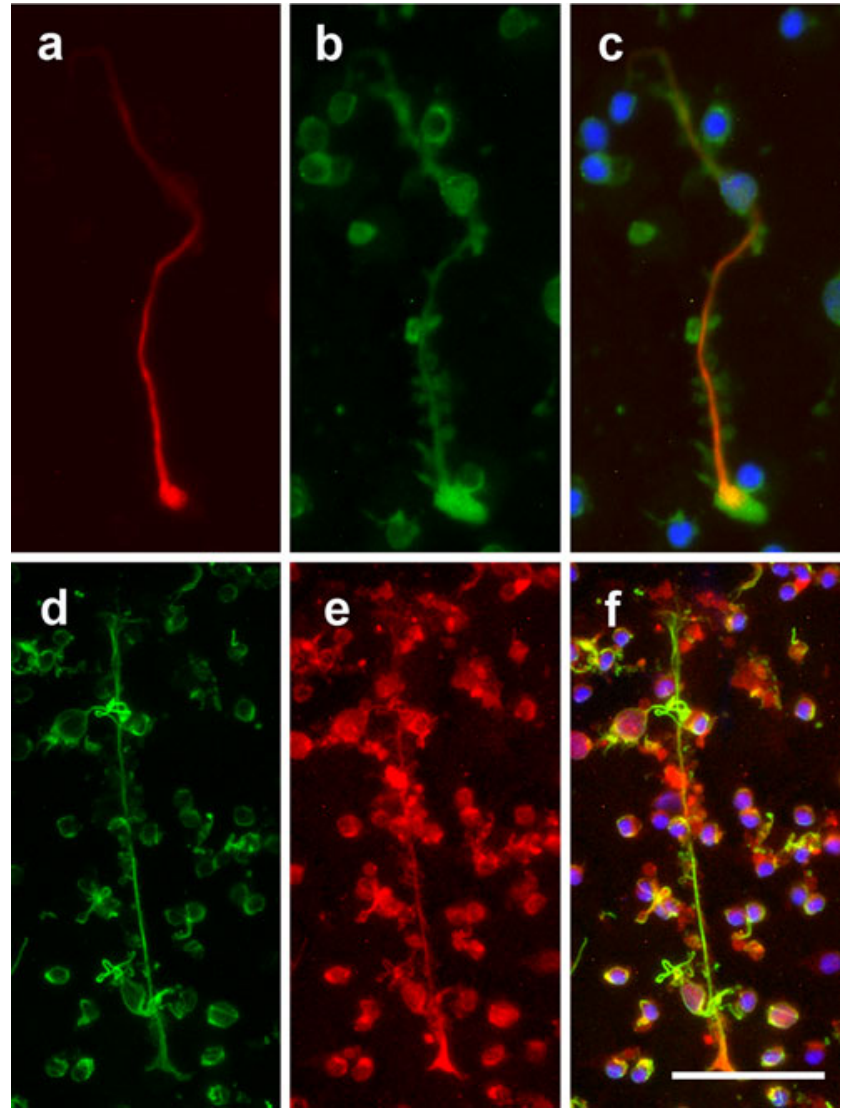

Fig. 3 Presence of FBPase in cytoplasm of Müller cells. Doubleimmunofluorescent staining of isolated Müller cells with antibodies against vimentin (a), FBPase (b, e), and $\alpha$-tubulin (d). c, f Merged images from, respectively, $\mathbf{a}, \mathbf{b}$ or from $\mathbf{d}$, e. Nuclei were counterstained with DAPI. Bar $50 \mu \mathrm{m}$
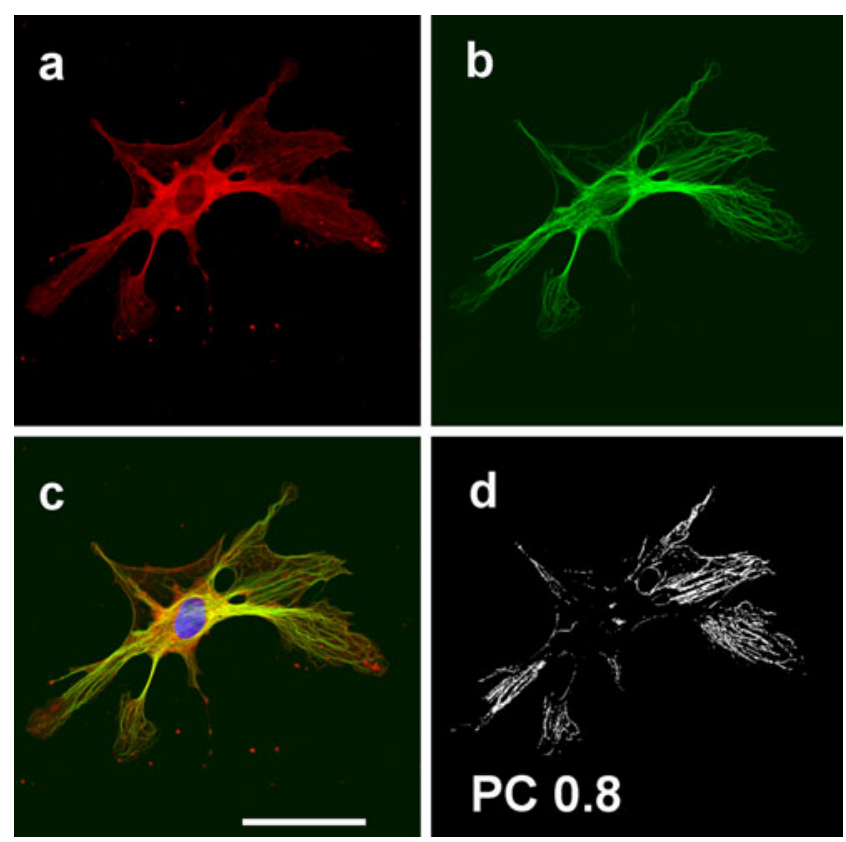

Fig. 4 Co-localization of FBPase (a) with $\alpha$-tubulin (b) in an isolated retinal astrocyte. The nucleus in the merged image was counterstained with DAPI (c). Graphical representation of Pearson's correlation coefficient $(P C)$ for FBPase colocalization with $\alpha$-tubulin (d). Bar $40 \mu \mathrm{m}$

only within the nuclei of proliferating cells (Fig. 6). Neither FBPase (Fig. 2) nor aldolase exhibited nuclear localization in the adult retina (Fig. 7), but the aldolase A antiserum strongly stained nuclei of cultured proliferating Müller cells (Fig. 8).

\section{Discussion}

FBPase, which catalyzes the practically irreversible reaction of fructose-1,6-bisphosphate hydrolysis to fructose-6phosphate, is a regulatory enzyme of gluconeogenesis and glyconeogenesis. According to our results, the location of FBPase in the rat retina corresponds closely to the localization of glycogen particles and to that of the enzymes of glycogen metabolism, e.g., glycogen phosphorylase and glycogen synthase, as described previously (Newell and Kurimoto 1963; Pfeiffer-Guglielmi et al. 2005).

The activity of FBPase in the whole rat retina is comparable with that determined previously in Amphibia (Goldman 1988); this suggests that gluconeogenesis also occurs in the retina of mammals. However, of note, the activity of FBPase in the rat retina is at least ten-fold lower than its activity in other tissues synthesizing glycogen from non-carbohydrates, e.g., in the lungs (Rakus et al. 2000) or skeletal muscles (Rakus and Dzugaj 2000). Thus, we can hypothesize that gluconeogenesis does not play a signifi- 
Fig. 5 Co-localization of FBPase (a, e) with vimentin (b) and $\alpha$-tubulin (f) in primary culture of Müller cells. Images c, $\mathbf{g}$ represent merged images of $\mathbf{a}, \mathbf{b}$ or of $\mathbf{e}, \mathbf{f}$, respectively. The nuclei were counterstained with DAPI. Images $\mathbf{d}, \mathbf{h}$ show graphical representation of Pearson's correlation coefficient $(P C)$ for FBPase co-localization with vimentin or $\alpha$-tubulin, respectively. Bars $40 \mu \mathrm{m}$
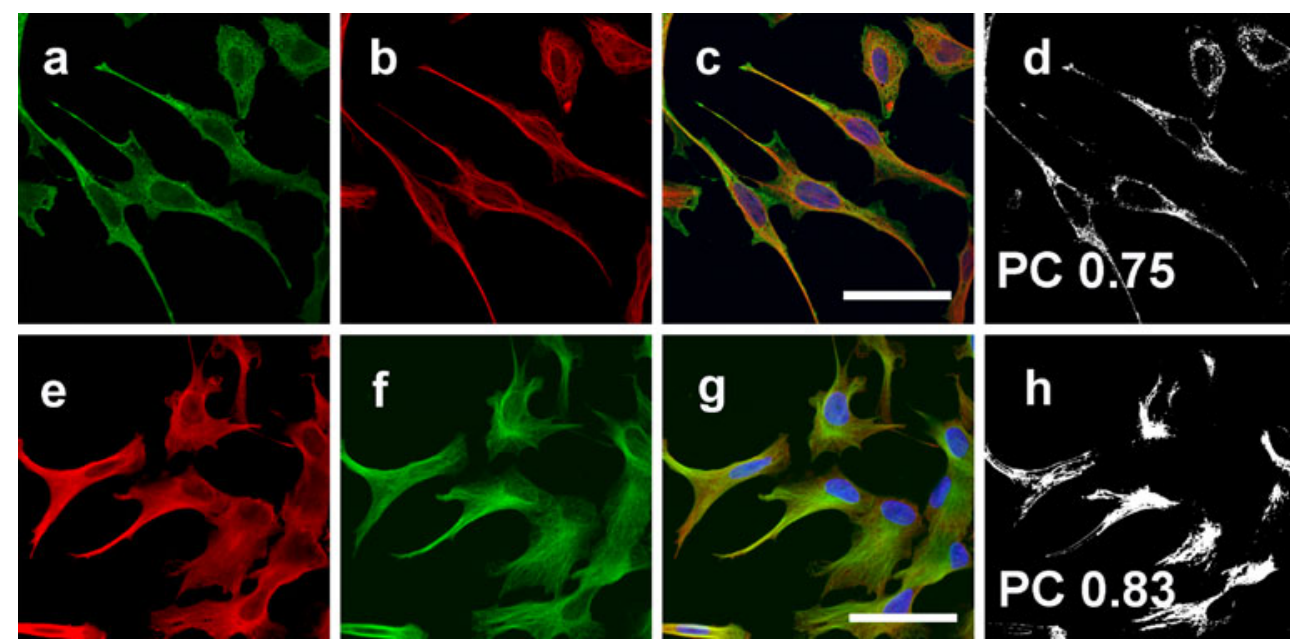

cant role in retinal energy homeostasis but is an auxiliary process enabling the removal of excess lactate and glutamate from the vicinity of neurons.

On the other hand, FBPase might be engaged in the regulation of the velocity of the retinal glycolysis forming the so-called substrate cycle with PFK. The substrate cycle is a mechanism of metabolic flux regulation based on the simultaneous activation and inhibition of enzymes catalyzing reactions proceeding in opposite directions, such as example FBPase and PFK (Newsholme and Start 1976). To achieve a significant efficiency of the substrate cycle, similar activities of both the enzymes are required. Consequently, because of the large difference between PFK and FBPase activities in the retina, the substrate cycle seems unlikely to regulate glycolysis or gluconeogenesis in this tissue.

Both the IPL and OPL are regions of high activity of synaptic transmission of retinal neurons and are areas in which numerous connections between neuronal and glial cells, mainly the Müller cells, are formed (Newman 2004; Bringmann et al. 2009). The presence of FBPase, a key enzyme of gluconeogenesis, in these layers confirms the hypothesis that glycogen synthesis from lactate and glutamate is a mechanism for the removal of retinal monocarboxylates during periods of high synaptic activity (Goldman and Witkovsky 1987; Coffe et al. 2004).

The physiological role of FBPase is commonly assumed to be restricted to its participation in glucose/glycogen
Fig. 6 Immunofluorescent localization of aldolase A, FBPase, and $\mathrm{Ki}-67$ in rat neonatal retinal sections. Labeling by antibodies against Ki-67 (b) with propidium-iodidecounterstained nuclei (a) and merged image of $\mathbf{a}, \mathbf{b}(\mathbf{c})$. Double-labeling with antibodies against muscle aldolase (d) and Ki-67 (e) and merged image of d, e (f). Double-labeling with antibodies against FBPase (g) and $\mathrm{Ki}-67$ (h) and merged image of $\mathbf{g}, \mathbf{h}$ (i). Merged images reveal co-localization of aldolase and FBPase with Ki-67. Bar $15 \mu \mathrm{m}$
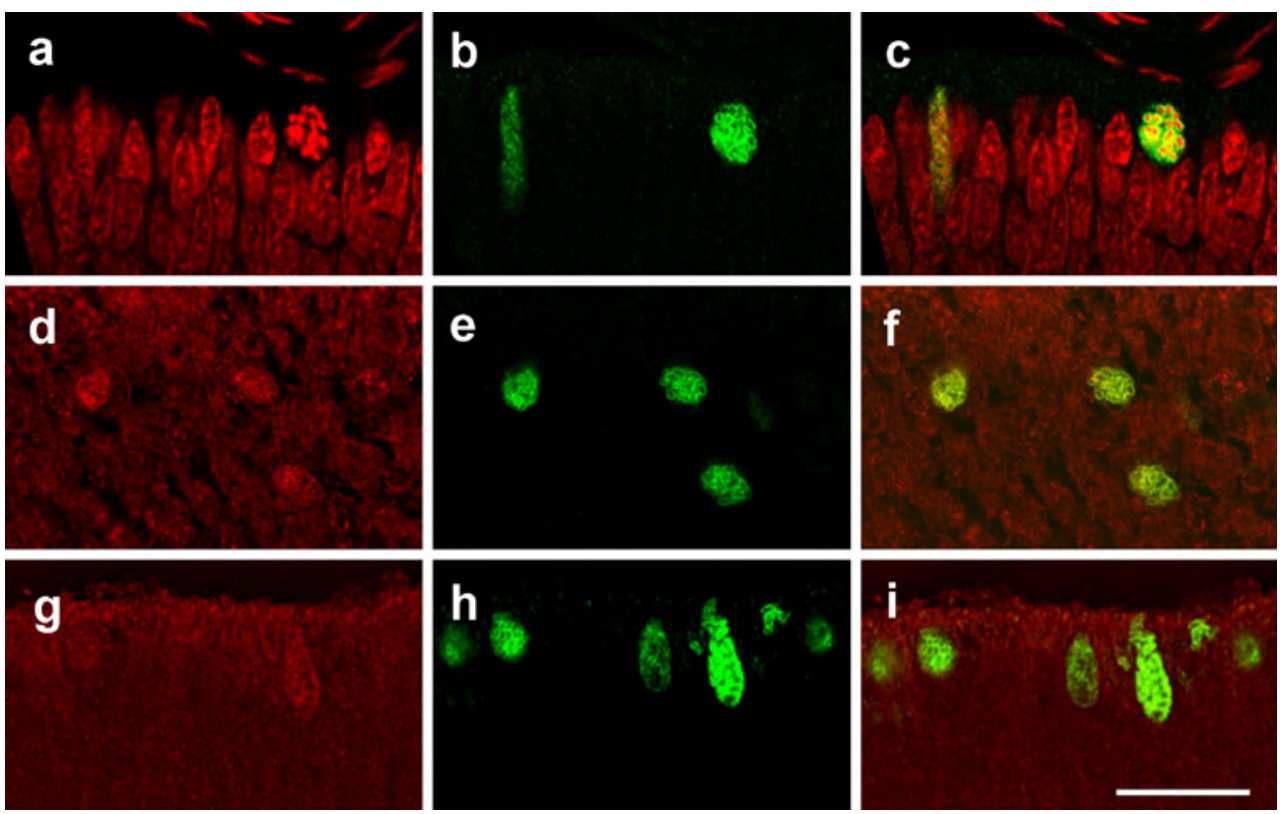

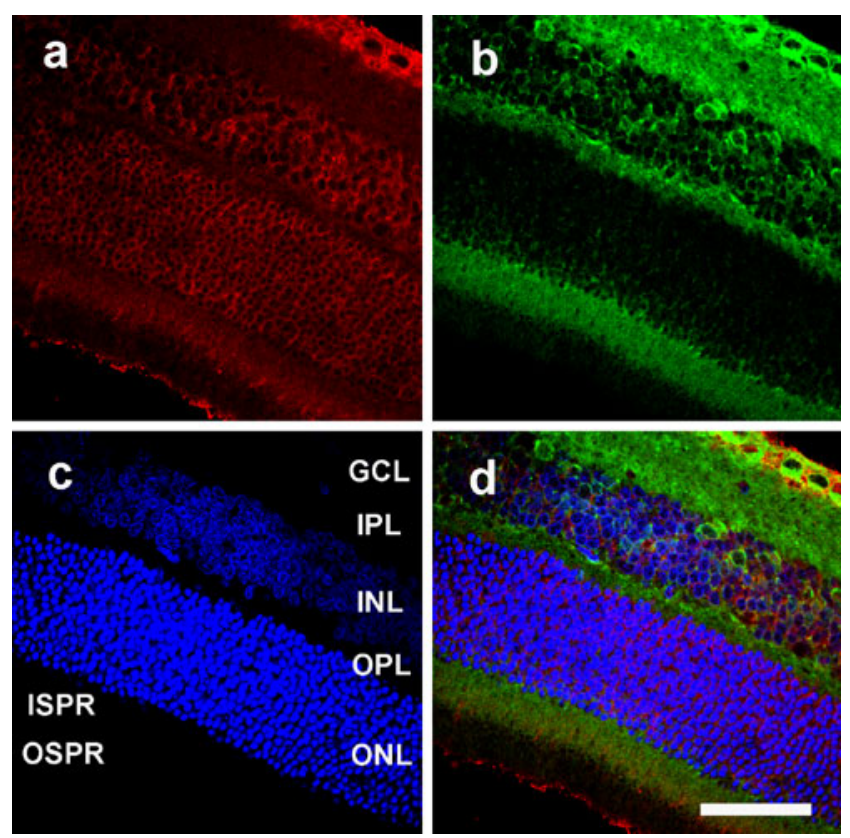

Fig. 7 Immunofluorescent localization of aldolase A (a) and aldolase $\mathrm{C}(\mathbf{b})$ in radial sections of adult rat retina $(G C L$ ganglion cell layer, $I P L$ inner plexiform layer, $I N L$ inner nuclear layer, $O P L$ outer plexiform layer, $O N L$ outer nuclear layer, $I S P R$ inner segments of photoreceptors, $O S P R$ outer segments of photoreceptors). Nuclei were counterstained with DAPI (c). Merged image from a-c (d). Bar $40 \mu \mathrm{m}$

synthesis. However, the reaction catalyzed by FBPase might also be regarded as part of the pentose phosphate pathway: the product of FBPase reaction, upon isomerization to glucose-6-phospate, becomes a substrate for glucose-6-phosphate dehydrogenase (G6PDH; Rakus et al. 2000). G6PDH, which catalyzes the first reaction of the pentose phosphate pathway, viz., the reduction of NADP to $\mathrm{NADPH}$, plays a key role in maintaining the normal redox status of cells and thus in the protection of cells against reactive oxygen species.

The rate of the pentose phosphate pathway in retina is relatively high, and NADPH generated in this pathway is utilized for stabilization of intracellular levels of reduced glutathione; this is presumed to be the main defense system protecting the eye against oxidative stress (Ganea and Harding 2006). Thus, FBPase, by participating in NADPH synthesis, might indirectly influence the protection of the retina against the toxic effect of oxygen. FBPase possibly plays the same dual gluconeogenic and antioxidant physiological role in the outer limiting membrane, the region in which multiple connections between the Müller cells and photoreceptors are formed (Williams et al. 1990). The inner segment of the photoreceptor is a region of high glycolytic activity (Lowry et al. 1961). The phosphocreatine shuttle has been postulated to transport high-energy phosphate groups from the inner to the outer segment for ATP production (Hsu and Molday 1994). The presence of a key enzyme of glycogen metabolism, viz., glycogen phosphorylase (Rothermel et al. 2008), and of glycogen particles (Newell and Kurimoto 1963) in the inner segments of photoreceptors indicates that glycogen might be used in the segment as a source of glucose for glycolysis. Thus, the presence of FBPase within the inner segments of photoreceptors suggests that glyconeogenesis is an additional pathway of energy accumulation therein and might be used to sustain phototransduction in the outer segment during hypoglycemia.

FBPase isozymes differ in their physiological properties. Testing their expression in the rat retina, we have found that this tissue expresses exclusively the muscle isozyme of FBPase. A previous study (Löffler et al. 2001) has demonstrated that rat brain neurons express the liver FBPase isozyme, whereas both isozymes are expressed in brain astrocytes. This inconsistency between our result and those of Löffler et al. (2001) suggests the presence of a distinct expression pattern in the rat brain and retina. Such distinctions in the expression of the glycogen phosphorylase isozymes have been shown to reflect differences in the regulation of brain and retinal glycogenolysis, suggesting a local specialization of the retinal cells (Pfeiffer-Guglielmi et al. 2005).

Muscle FBPase, in contrast to the liver form, is highly sensitive to inhibition by AMP, NAD, and $\mathrm{Ca}^{2+}$, and under physiological concentrations of the inhibitors, the enzyme is almost completely inactive (Rakus and Dzugaj 2000; Gizak et al. 2004). Thus, the provision of substrates for NADP reduction and/or glycogen synthesis from noncarbohydrates should cease in their presence. The only
Fig. 8 Localization of aldolase $\mathrm{A}$ (a) and aldolase C (b) in primary culture of Müller cells. Merged image showing counterstaining with DAPI (c). Bar40 $\mu \mathrm{m}$
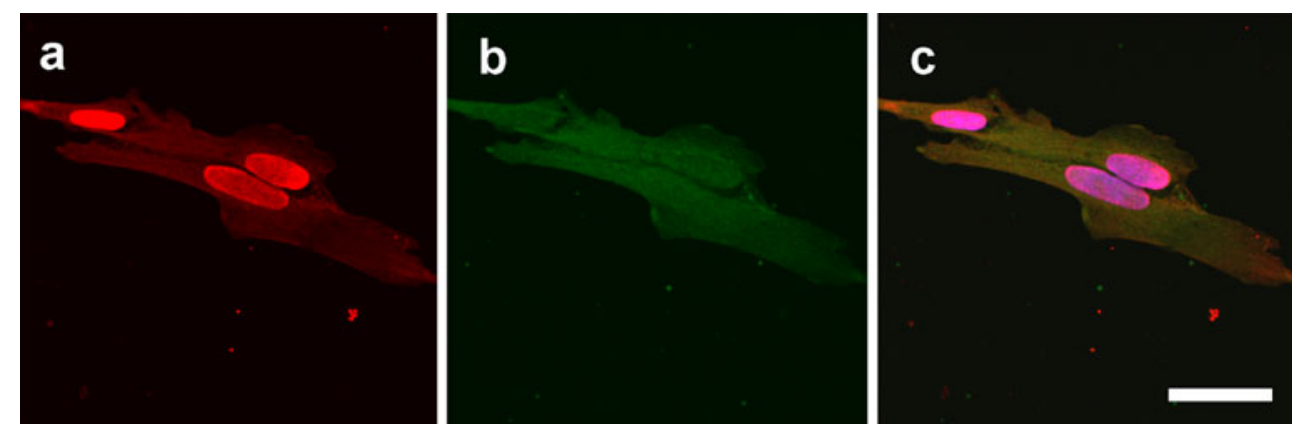
known factor desensitizing muscle FBPase to the action of its inhibitors is the muscle isozyme of aldolase, viz., aldolase A (Rakus et al. 2003, 2004; Mamczur et al. 2005). Studying the distribution of FBPase in the rat retina, we have found that the enzyme co-localizes with aldolase. The brain isozyme of aldolase (aldolase C) has been shown to be the principal form of the enzyme in neural cells in which it occurs as a part of the heterotetrameric A-C hybrid set (Beemer et al. 1982). Our immunofluorescent studies with the aldolase-isozyme-specific antibodies indicate that, in the rat retina, the amount of aldolase A is comparable with that of aldolase C. In contrast to earlier immunochemical studies (Caffé et al. 1994), we have found that both aldolase isozymes are expressed across all the retinal layers, except for ONL in which only the muscle aldolase is present.

A microscopic examination of wax sections of the retina have revealed that FBPase is present mainly in cells characterized by GFAP fluorescence, i.e., the glia cells. Among the retinal glia, the highest capacity for glyconeogenesis from lactate and glutamate is possessed by Müller cells (Goldman 1990). Therefore, FBPase localization is possibly confined to these cells. However, the analysis of freshly isolated rat Müller cells has shown that FBPase is evenly distributed within the cells, and as seen in Fig. 2, the FBPase immunostaining pattern of wax sections of the retina does not resemble the morphology of the Müller cells extending from the inner to the outer limiting membrane (Bringmann et al. 2009). Thus, neither the cell shape nor the subcellular distribution of FBPase therein explains the strong immunoreactivity of the plexiform layers.

Evidently, the Müller cells are not the only retinal glia cells containing FBPase. Freshly isolated retinal astrocytes also express FBPase. This indicates that the resynthesis of glycogen from lactate, as a mechanism of monocarboxylate removal and/or the support of the pentose phosphate pathway, might be typical for all the glial cells and photoreceptors of the retina. Moreover, the high colocalization coefficient of FBPase and $\alpha$-tubulin implies that the latter protein is the structural basis for glyconeogenesis in the glial cells. The Ovádi group has demonstrated that several glycolytic enzymes (e.g., hexokinase, PFK, aldolase, triosephosphate isomerase, and pyruvate kinase) interact with the microtubular system of cells, and that this association leads to the formation of macromolecular structure and results in alterations in the catalytic properties of the enzymes (Ovádi et al. 2004).

Both FBPase and aldolase are expressed in primary cultures of Müller cells. However, the morphology of these cells in culture significantly changes; the cells de-differentiate and gain a capability for proliferation that remains unchanged for at least five passages of the culture (Guidry 1996). In such cells, aldolase A, but not C or FBPase, localizes within the cell nucleus. Unexpectedly, we have found that, during retinal development, not only aldolase A, but also FBPase localizes within the nuclei of proliferating cells.

Our earlier studies have revealed that FBPase localizes within the nuclei of cells that have the potential to proliferate but that are also at least partially differentiated: in some adult mammalian cardiomyocytes (Gizak and Dzugaj 2003), in mouse cardiomyocytes cell line (HL-1) stimulated with norepinephrine leading to their adult phenotype (Gizak et al. 2009), and in muscle satellite cells (Gizak et al. 2006). The nuclear localization of FBPase in the developing retina suggests that, also in this tissue, the cellular action of the enzyme is related in some manner to cell differentiation.

In contrast to FBPase, aldolase A seems to localize within the nuclei of all proliferating retinal cells, independently of the level of their differentiation. Previously, aldolase has been found in the nuclei of several cell types in which mitosis or karyokinesis occurs: in smooth muscle cells (Mamczur and Dzugaj 2008), cardiomyocytes (Mamczur et al. 2007), and hepatocytes (Sáez and Slebe 2000). Hence, we are tempted to assume that the retinal aldolase is a part of the cell division machinery.

In summary, our experiments have demonstrated that rat retinal cells express exclusively the muscle isozyme of FBPase. The enzyme localizes in the inner segments of photoreceptors and in the glial cells of the rat retina in which it is thought to be involved in the removal of the excess of lactate and glutamate from the vicinity of neurons. We suggest that the role of muscle FBPase goes beyond its gluconeogenic action, and that, in addition to participation in defense against reactive oxygen species, the enzyme also takes part in regulation of cell differentiation. Moreover, the muscle aldolase, viz., the enzyme desensitizing FBPase to the action of its inhibitors and, hence, enabling glucose-6-phosphate synthesis from noncarbohydrates, seems to be a multifunctional protein, presumably being involved in cell cycle progression.

Acknowledgements We are grateful to Dr. Agnieszka Gizak for stimulating discussion and linguistic assistance.

Open Access This article is distributed under the terms of the Creative Commons Attribution Noncommercial License which permits any noncommercial use, distribution, and reproduction in any medium, provided the original author(s) and source are credited.

\section{References}

Beemer FA, Vlug AM, Rijksen G, Hamburg A, Staal GE (1982) Characterization of some glycolytic enzymes from human retina and retinoblastoma. Cancer Res 42:4228-4232 
Bringmann A, Pannicke T, Biedermann B, Francke M, Iandiev I, Grosche J, Wiedemann P, Albrecht J, Reichenbach A (2009) Role of retinal glial cells in neurotransmitter uptake and metabolism. Neurochem Int 54:143-160

Caffé AR, Von Schantz M, Szél A, Voogd J, Van Veen T (1994) Distribution of Purkinje cell-specific zebrin-II/aldolase C immunoreactivity in the mouse, rat, rabbit, and human retina. J Comp Neurol 348:291-297

Coffe V, Carbajal RC, Salceda R (2004) Glycogen metabolism in the rat retina. J Neurochem 88:885-890

Ganea E, Harding JJ (2006) Glutathione-related enzymes and the eye. Curr Eye Res 31:1-11

Gerhardinger C, Costa MB, Coulombe MC, Toth I, Hoehn T, Grosu P (2005) Expression of acute-phase response proteins in retinal Müller cells in diabetes. Invest Ophthalmol Vis Sci 46:349-357

Gizak A, Dzugaj A (2003) FBPase is in the nuclei of cardiomyocytes. FEBS Lett 539:51-55

Gizak A, Majkowski M, Dus D, Dzugaj A (2004) Calcium inhibits muscle FBPase and affects its intracellular localization in cardiomyocytes. FEBS Lett 576:445-448

Gizak A, Wrobel E, Moraczewski J, Dzugaj A (2006) Changes in subcellular localization of fructose 1,6-bisphosphatase during differentiation of isolated muscle satellite cells. FEBS Lett 580:4042-4046

Gizak A, Zarzycki M, Rakus D (2009) Nuclear targeting of FBPase in HL- 1 cells is controlled by beta- 1 adrenergic receptor-activated Gs protein signaling cascade. Biochim Biophys Acta 1793:871877

Goldman SS (1988) Gluconeogenesis in the amphibian retina. Lactate is preferred to glutamate as the gluconeogenic precursor. Biochem J 254:359-365

Goldman SS (1990) Evidence that the gluconeogenic pathway is confined to an enriched Müller cell fraction derived from the amphibian retina. Exp Eye Res 50:213-218

Goldman SS, Witkovsky P (1987) Evidence for gluconeogenesis in the amphibian retina. Exp Eye Res 44:65-71

Guidry C (1996) Isolation and characterization of porcine Müller cells. Myofibroblastic dedifferentiation in culture. Invest Ophthalmol Vis Sci 37:740-752

Hsu S-Ch, Molday RS (1994) Glucose metabolism in photoreceptor outer segments. Its role in phototransduction and in NADPHrequiring reactions. J Biol Chem 269:17956-17959

Ishii M, Horio $\mathrm{Y}$, Tada $\mathrm{Y}$, Hibino $\mathrm{H}$, Inanobe A, Ito M, Yamada M, Gotow T, Uchiyama Y, Kurachi Y (1997) Expression and clustered distribution of an inwardly rectifying potassium channel, KAB-2/Kir4.1, on mammalian retinal Müller cell membrane: their regulation by insulin and laminin signals. Neuroscience 17:7725-7735

Ling KH, Marcus F, Lardy HA (1965) Purification and some properties of rabbit skeletal muscle phosphofructokinase. J Biol Chem 240:1893-1899

Löffler T, Al-Robaiy S, Bigl M, Eschrich K, Schliebs R (2001) Expression of fructose-1,6-bisphosphatase mRNA isoforms in normal and basal forebrain cholinergic lesioned rat brain. Int $\mathrm{J}$ Dev Neurosci 19:279-285

Lowry OH, Roberts NR, Schulz DW, Glow JE, Clark JR (1961) Quantitative histochemistry of retina. II. Enzymes of glucose metabolism. J Biol Chem 236:2813-2820

Mamczur P, Dzugaj A (2004) Nuclear localization of aldolase A in pig cardiomyocytes. Histol Histopathol 19:753-758

Mamczur P, Dzugaj A (2008) Aldolase A is present in smooth muscle cell nuclei. Acta Biochim Pol 55:799-805
Mamczur P, Rakus D, Gizak A, Dus D, Dzugaj A (2005) The effect of calcium ions on subcellular localization of aldolase-FBPase complex in skeletal muscle. FEBS Lett 579:1607-1612

Mamczur P, Dus D, Dzugaj A (2007) Colocalization of aldolase and FBPase in cytoplasm and nucleus of cardiomyocytes. Cell Biol Int 31:1122-1130

Newell FW, Kurimoto S (1963) Histochemistry of the retina in the alloxan-diabetic rat. Br J Ophthalmol 47:596-600

Newman EA (2004) Glial modulation of synaptic transmission in the retina. Glia 47:268-274

Newsholme EA, Start C (1976) Regulation in carbohydrate metabolism in muscle. In: Newsholme EA, Start C (eds) Regulation in metabolism. Wiley, London, pp 88-145

Oskam R, Rijksen G, Staal GE, Vora S (1985) Isozymic composition and regulatory properties of phosphofructokinase from welldifferentiated and anaplastic medullary thyroid carcinomas of the rat. Cancer Res 45:135-142

Ovádi J, Orosz F, Hollán S (2004) Functional aspects of cellular microcompartmentation in the development of neurodegeneration: mutation induced aberrant protein-protein associations. Mol Cell Biochem 256-257:83-93

Pfeiffer-Guglielmi B, Francke M, Reichenbach A, Fleckenstein B, Jung G, Hamprecht B (2005) Glycogen phosphorylase isozyme pattern in mammalian retinal Müller (glial) cells and in astrocytes of retina and optic nerve. Glia 49:84-95

Poitry-Yamate CL, Tsacopoulos M (1991) Glial (Müller) cells take up and phosphorylate $3 \mathrm{H}-2$-deoxy-D-glucose in a mammalian retina. Neurosci Lett 122:241-244

Poitry-Yamate CL, Tsacopoulos M (1992) Glucose metabolism in freshly isolated Müller glial cells from a mammalian retina. J Comp Neurol 320:257-266

Poitry-Yamate CL, Poitry S, Tsacopolous M (1992) Lactate released by Müller cells is metabolized by photoreceptors from mammalian retina. J Neurosci 15:5179-5191

Rakus D, Dzugaj A (2000) Muscle aldolase decreases muscle FBPase sensitivity toward AMP inhibition. Biochem Biophys Res Commun 275:611-616

Rakus D, Skalecki K, Dzugaj A (2000) Kinetic properties of pig (Sus scrofa domestica) and bovine (Bos taurus) D-fructose-1,6bisphosphate 1-phosphohydrolase (F1,6BPase): liver-like isozymes in mammalian lung tissue. Comp Biochem Physiol [B] Biochem Mol Biol 127:123-134

Rakus D, Pasek M, Krotkiewski H, Dzugaj A (2003) Muscle FBPase in a complex with muscle aldolase is insensitive to AMP inhibition. FEBS Lett 547:11-14

Rakus D, Pasek M, Krotkiewski H, Dzugaj A (2004) Interaction between muscle aldolase and muscle fructose 1,6-bisphosphatase results in the substrate channeling. Biochemistry 43:1494814957

Rothermel A, Weigel W, Pfeiffer-Guglielmi B, Hamprecht B, Robitzki AA (2008) Immunocytochemical analysis of glycogen phosphorylase isozymes in the developing and adult retina of the domestic chicken (Gallus domesticus). Neurochem Res 33:336-347

Sáez DE, Slebe JC (2000) Subcellular localization of aldolase B. J Cell Biochem 78:62-72

Towbin H, Staehelin T, Gordon J (1979) Electrophoretic transfer of proteins from polyacrylamide gels to nitrocellulose sheets: procedure and some applications. Proc Natl Acad Sci 76:4350 4354

Williams DS, Arikawa K, Paallysaho T (1990) Cytoskeletal components of the adherens junctions between the photoreceptors and the supportive Müller cells. J Comp Neurol 295:155-164 